\title{
Inovando a aprendizagem através da utilização do método simulação em unidades curriculares teóricas no curso de administração
}

\author{
Sefisa Bezerra ${ }^{\mathrm{a}}$, Levi Leonido ${ }^{\mathrm{b}}$, Elsa Morgado ${ }^{\mathrm{c}}$, Mário Cardoso ${ }^{\mathrm{d}}$, Eduardo Dias $^{\mathrm{e}}$ \\ ${ }^{\mathrm{a}}$ Universidade Estatual do Vale do Acaraú, Sobral, Brasil, sefisaquixada@gmail.com, ${ }^{\mathrm{b}}$ Universidade \\ de Trás-os-Montes e Alto Douro, Vila Real, Portugal. Universiade Católica Portuguesa (CITAR), \\ Porto, Portugal, levileon@utad.pt, ${ }^{\mathrm{c}}$ UTAD, Centro de Estudos Filosóficos e Humanísticos da \\ Universidade Católica - Braga, Portugal, levielsa@utad.pt, ${ }^{\mathrm{d}}$ Instituto Politécnico de Bragança, \\ Bragança, Portugal, cardoso@ipb.pt, 'Universidade Estatual do Vale do Acaraú, Sobral, Brasil, \\ días sobral@hotmail.com
}

\begin{abstract}
Resumo
$\mathrm{Na}$ educação, atualmente, existem várias metodologias sistematizadas para promover a aprendizagem ativa que estão se consagrando nos meios acadêmicos, principalmente nas ciências aplicadas. Dentre elas está o Método de Simulação, que consiste em explorar técnicas, habilidades e alguns aspectos comportamentais do aluno, utilizando a sala de aula como um modelo de representação de um ambiente empresarial. Esse estudo pretende apresentar a importância da prática da aprendizagem Simulação como um recurso complementar em disciplinas que, a rigor, seriam tratadas como unidades curriculares somente teóricas, criando valor agregado pelo esforço mental e criativo tanto do aluno como do professor. Estudo de natureza qualitativa com abordagem vivencial onde apresentamos relatos de aprendizagem sem a pretensão de gerar conclusões sobre a temática. Devemos mencionar alguns de seus beneficios como: a intensa participação e interesse dos alunos como agentes do processo de aprendizagem e descoberta, tendo, naquele momento experimentado sucessos e fracassos em virtude do desenvolvimento do exercício da tomada de decisão, a ativação de fatores motivacionais nos alunos, a possibilidade de perceberem e usarem seus aspectos comportamentais de liderança e de desenvolvimento de equipes, a percepção da ambiência do experimento, além do uso eficiente dos escassos recursos físicos, materiais, tecnológicos e do tempo.
\end{abstract}

Palavras chave: Simulação, métodos ativos, aprendizagem 


\begin{abstract}
In education, currently, there are several systematized methodologies to promote active learning that are being consecrated in academic circles, especially in the applied sciences. Among them is the Simulation Method, which consists of exploring techniques, skills and some behavioral aspects of the student, using the classroom as a representation model of a business environment. This study intends to present the importance of the practice of learning Simulation as a complementary resource in disciplines that, strictly speaking, would be treated as only theoretical curricular units, creating added value by the mental and creative effort of both the student and the teacher, enabling their understanding of much more clear and unforgettable, since his understanding has been up to the level of emotions and feelings. A qualitative study with experiential approach, where even if we do not intend to generate conclusions on the subject, we must mention some of its benefits such as:the intense participation and interest of the students as agents of the process of learning and discovery, having at that time experienced successes and failures due to the development of the decision making exercise, the activation of motivational factors in the students, the possibility of perceiving and using their behavioral aspects of and the efficient use of scarce physical, material, technological and time resources.
\end{abstract}

Keywords: Simulation, active methods, learning

\title{
1. Introdução
}

A prática de Simulação, embora já venha sendo utilizada há décadas em alguns países, apenas no final dos anos 90, começou a ser efetivamente utilizada no Brasil, e ainda principalmente, na área de negócios, aonde algumas universidades chegaram até a incluir como unidade curricular. Simulação Gerencial ou somente Simulação é um método de aprendizagem que se baseia na abordagem vivencial, o que pressupõe o envolvimento dos alunos no processo, permitindo a aplicação de conhecimentos adquiridos anteriormente através do comprometimento e da experiência de um sentimento pessoal real de sucesso ou fracasso pelos resultados obtidos (Marion \& Marion, 2006). Esse estudo aborda o uso desse método destacando-o como um recurso didático na formação, no aprendizado e na prática do estudante de nível superior e seus resultados percebidos.

Trata-se de um estudo qualitativo, não se tendo a pretensão de relatos conclusivos sobre a temática. Serão relatadas práticas ocorridas em sala de aula que tiveram, no exercício da 
sua realização a intenção de mostrar o desenvolvimento de processos de gestão e vários desafios gerenciais pelo qual um administrador pode vir a passar no exercício da sua função e ainda como se desenvolveram experimentos antes se transformarem em teorias. A simulação ainda é uma prática de aprendizagem inovadora no curso de administração por ser necessária uma preparação prévia e apurada de métodos de aprendizagem por parte do docente e por seu caráter interdisciplinar. Foi utilizada como um recurso didático complementar de aprendizagem nas unidades curriculares Teoria dos Jogos e Introdução a Administração, em turmas de semestres iniciais e finais no curso de Administração numa universidade pública estadual localizada na cidade de Sobral, estado do Ceará, com a finalidade de proporcionar aos alunos uma vivência real de administração. Por meio dessa atividade os alunos foram instigados a agir como administradores, observando todos os princípios que norteiam a ciência, sua prática, de modo a entender o seu processamento visto seu caráter pragmático e instrumental e que, nem sempre a universidade consegue alcançar em unidades desenvolvidas somente a partir de aulas expositivas.

\section{Enquadramento}

As universidades vivem, desde o último século, numa luta permanente no sentido de atualização dos conhecimentos científicos e tecnológicos.

Novas áreas do conhecimento influenciaram e passaram a gerar complexidade no mundo da informação, áreas como biotecnologia, robótica, inteligência artificial, entre outras, dificultando o modo de conhecer e de ensinar. A inteligência está a prova o tempo inteiro. Como disse Nóvoa (2015, p. 235) “o conhecimento é a matéria-prima da aprendizagem que tem como questão central, remetendo para à Pedagogia, dar sentido à massa disforme de dados e informações que está ao alcance dos 'polegares'. É este processo de apropriação e de interligação que define a aprendizagem”.

Os cursos superiores nem sempre conseguem acompanhar esse ritmo, ainda não se avaliou a exata distância dessa realidade. Paviani (2003, p. 20) afirmou que "os conteúdos fornecidos pelo avanço científico são ensinados sem o correspondente avanço nos processos de ensino." O problema da incompletude das pesquisas científicas em atender as necessidades da população tem ligação direta com a inadequação do repasse dos conceitos e dos métodos de aprendizagem das universidades e dos acelerados movimentos tecnológicos, sociais, dentre outros. Educação superior passou a ser uma missã

o para as instituições especializadas, preparar pessoas para reger instituições de toda espécie, fins e objetivos passou a exigir uma apurada eficiência da instituição propriamente dita, dos docentes, da estrutura, dos conteúdos, das unidades e da responsabilidade perante a condição de lidar com a inteligência de outrem, com o ato de ensinar e com as manifestações do aprender. Scheffler (1974, apud Moreira, 2003, p. 131) reconhece, "em ensino, a grande diferença que existe em obter êxito e tentar obtê-lo. Assim,...o êxito em 
Inovando a aprendizagem através da utilização do método simulação em unidades curriculares teóricas no curso de administração

ensinar implica em que o aluno aprenda, seja lá o que for que se está ensinando. Ninguém pode dizer que ensinou se o aluno não aprendeu".

Da mesma forma que há autores que concordam com a flexibilidade da inteligência como um elemento importante no ensino, pois as pessoas podem avaliar suas forças, suas fraquezas e descobrirem formas de reinventarem-se, seja corrigindo ou remediando-se, para prosseguirem no que podem fazer melhor e viverem melhor, assim percebemos a aprendizagem, o que mais importa é a sua validade em determinadas situações, explicamos melhor, é o resultado que poderemos obter ao utilizarmos essa ou aquela técnica.

Scheffler (1974, apud Moreira, 2003, pp. 132-133) distingue dois estágios de aprendizagem: Passiva e Ativa: Passiva: o professor fala, disserta, expõe, seus "alunos" estão ouvindo, ele obtém êxito em dizer, mas não obtém êxito automático em ensinar. Não requer exercitação nem desenvolvimento de atitudes dos alunos, daí é muito mais simples de ser obtida. Ativa: o professor utiliza vários meios de aprendizagem, como métodos de caso, resolução de problemas, simulações, elaboração e avaliação de projetos, manipulação de situações hipotéticas, vai até onde houver criatividade e aceitação dos alunos. Necessita de maior preparação do professor e uma atenta condução da aprendizagem individual e coletiva e dos meios empregados.

Quando o aluno busca o ensino superior, normalmente, ele vai ao encontro de uma área específica do conhecimento, modifica suas atitudes, passa a dar valor a novos conhecimentos e novas experiências, cria grupos de afinidade, enfim, desenvolve outras maneiras de compreensão, em substituição a aprendizagem repetitiva ou mecanizada. Há uma abertura a novas formas de aprendizagem, a inteligência se move e a instituição tem que estar preparada.

Segundo Abreu e Masetto (1982) qualquer que seja a forma adotada de ensino da instituição existem princípios comuns a todos os que se preocupam com a aprendizagem do aluno, são eles: 1 -Toda aprendizagem, precisa ser significativa para quem aprende, precisando que ele se envolva como pessoa com ideias, sentimentos, cultura, sociedade e que suscite, modificações no comportamento do aluno (grifo meu). 2 -Toda aprendizagem é pessoal e envolve mudança de comportamento. 3 - Toda aprendizagem precisa visar objetivos realísticos, para que se seja significativo e possibilite uma práxis, senão talvez não cause interesse. 4 - Toda aprendizagem precisa ser acompanhada de um feedback imediato. 5 - Toda aprendizagem precisa ser embasada em um bom relacionamento interpessoal.

Barbosa e Moura (2013, p. 52) afirmaram que "complementando esses requisitos de aprendizagem, é indispensável que eles(alunos) sejam capazes de exercer valores e condições de formação humana, considerados essenciais no mundo do trabalho contemporâneo, tais como: conduta ética, capacidade de iniciativa, criatividade, flexibilidade, autocontrole, comunicação, dentre outros”. Isso não há dúvida de que, mesmo 
com toda complexidade, não deverá ser substituído ou desmerecido dentro de um processo humano como é a aprendizagem.

A forma de lidar com a aprendizagem e o ensino é que define se a metodologia é válida, as inovações pedagógicas não farão sentido se não forem adotadas, e ainda, mudanças legais e reorganização curricular nem sempre possibilitam e nem geram os resultados esperados. É nessa perspectiva que metodologias ativas se apresentam como contribuição relevante na criação de ambientes de aprendizagem contextualizada, com impactos de grande interesse e resultados mais pontuais

De acordo com o objetivo de cada ciência se define o método de lidar. Nas ciências sociais aplicadas há uma incessante busca de resultados através de procedimentos específicos na busca da efetividade e do atendimento à sociedade, então é essencial o reconhecimento dessas características na definição do processo de ensino, da metodologia a ser utilizada. A partir daí, cada instituição define como fazer a abordagem em sala de aula e como irá atingir sua proposta pedagógica. Fica inviável e até impossível que se possa construir uma proposta pedagógica que contenha todos os elementos que contemplem todas as ciências trabalhadas por àquela instituição, e ainda venha definida, de forma fechada, a proposta pedagógica com procedimentos e métodos inseridos. Cada curso, de acordo com suas especificidades, define junto com seus atores a adequação do método, a forma de aprendizagem, como melhor aproveitar a experiência dos alunos na busca dos resultados esperados. Entendemos que um bom método é aquele em que o aluno tem participação ativa e é direcionado pelo professor. Para se envolver ativamente no processo de aprendizagem, o aluno deve interagir a todo instante, seja lendo, escrevendo, perguntando, discutindo, resolvendo problemas, desenvolvendo projetos. "Nesse sentido, as estratégias que promovem aprendizagem ativa podem ser definidas como sendo atividades que ocupam o aluno em fazer alguma coisa e, ao mesmo tempo, o leva a pensar sobre as coisas que está fazendo (Silberman, 1996, apud Barbosa \& Moura, 2013, p. 55).

Vale ressaltar que metodologias ativas de aprendizagem envolvem métodos ativos de ensino, ou melhor, para tornar o momento de ensino aprendizagem mais produtivo e colaborativo podemos usar diversas estratégias de ensino, criando valor agregado pelo esforço mental e criativo, algumas dessas estratégias já são conhecidas como as que seguem: criação de sites ou de redes sociais visando troca de informações e atualizações; simulação de processos e casos específicos por área; produção de mapas conceituais para aprofundamento e esclarecimento de assuntos; brainstorming para de solução de problemas; brainstorming para lançamento de ideias, serviços ou produtos; seminários; projeção de filmes alusivos a temática estudada; orientação e criação de vídeos educativos sobre a temática estudada; gamefication; prototipagem e testagem de produtos ou serviços; leitura orientada; debates sobre temas da atualidade; rodas de conversas; estudos de caso sobre 
Inovando a aprendizagem através da utilização do método simulação em unidades curriculares teóricas no curso de administração

uma área específica; discussão de temáticas inovadoras para a formação profissional; visitas técnicas e orientadas; excursões e exposições vivenciadas; palestras interativas.

A definição da estratégia e o recurso ou instrumental a ser utilizado vai até onde houver a criatividade, o atingimento da finalidade do assunto que estiver sendo tratado, a unidade curricular permitir e principalmente, até onde os alunos estiverem absorvendo e aceitando.

Existem também metodologias sistematizadas para promover a aprendizagem ativas que estão se consagrando nos meios acadêmicos, principalmente nas ciências aplicadas, onde a relação teoria e prática é muito buscada. Essas metodologias trazem para sala de aula possibilidades de resolutividade de casos reais, que além de envolver o aluno numa condição de vivência, de conhecimento de conjuntura e de aspectos que ainda lhes ajudarão a gerar juízo de valor, desenvolver e aprimorar inteligências como a interpessoal, intrapessoal, emocional, as presentes na própria matriz curricular, além das competências desejadas. São elas: aprendizagem baseada em problemas, aprendizagem baseada em projetos, peer instruction, just in time teaching, aprendizagem baseada em times, método de caso e simulações.

Buscamos aqui apresentar a importância do uso de um método ativo específico de aprendizagem que é a simulação e é muito propício para os cursos das sociais aplicadas, especificamente Administração pois levará a uma diferenciação em relação às tradicionais formas de aprendizagem.

Conforme Marion e Marion(2006) o método de simulação empresarial é utilizado para capacitação gerencial, explora muitas técnicas, habilidades, explora também alguns aspectos comportamentais utilizando um modelo de ambiente empresarial. "Simulando não apenas o funcionamento de uma empresa, mas principalmente o seu gerenciamento interno ou do seu relacionamento externo" (Marion \& Marion, 2006, p.85). Tem como principais características a possibilidade de revisão e assimilação de conceitos apreendidos das unidades curriculares, os participantes agem ativamente na gestão das empresas simuladas, o processo é cíclico, fornecem oportunidades de participação interativa através de demonstrações ou servir de suporte a ConcepTests, incentiva e orienta o processo de descoberta do aluno, proporcionando-lhe um ambiente divertido e atraente no qual poderá fazer perguntas e ter feedback para descobrir a resposta, apesar de não substituírem as situações reais, vários estudos têm mostrado que sua utilização gera bons resultados em questões conceituais sobre o assunto, motiva a participação do aluno, possibilita que se façam coisas que são impossíveis de serem feitas no mundo real, uma simulação pode levar à aprendizagem relativamente rápida e muito eficaz de assuntos difíceis, dentre outras.

Como benefícios desse método para o meio acadêmico podemos citar que: os alunos tornam-se agentes ativos do processo de aprendizagem, possibilitando experimentar sucessos ou fracassos em virtudes das decisões tomadas, o que é muito motivador e torna a 
aprendizagem também dinâmica, permite a práxis em sala de aula e em tempo compactado e porque não dizer real, uso das ferramentas de apoio didático e de gestão e ainda há a possibilidade de trabalhar aspectos comportamentais, de liderança e desenvolvimento de equipes. Mas há também limitações nesse método, como: podem aparecer o desmedido valor a busca por resultados positivos como se a simulação fosse uma disputa, há que se ter consciência que é uma simulação, na vida real, podem surgir outras variáveis não previstas nesse método, o tempo de realização, embora planejado, não é igual ao de ações reais, dentre outras questões esses foram os principais limitadores. Há de se destacar o papel do professor orientador, condutor do processo, que deve ser conhecedor da didática da aprendizagem e do método, deve ter conhecimento sistêmico da ciência que trabalha a simulação, ter uma boa experiência de gestão e ainda consideramos imprescindível ter criatividade na condução do processo.

\section{Metodologia}

Estudo de natureza qualitativa com abordagem vivencial onde apresentamos relatos de aprendizados desenvolvidos através do método de simulação. Com a simulação os alunos compreenderam melhor a aplicação e a prática da aprendizagem dos conceitos e uso dos recursos gerenciais. Foi realizado com estudantes do curso de Administração de uma universidade publica do estado do Ceará, Brasil, com matrículas ativas, dados do primeiro semestre de 2018 (matrículas semestrais), nas unidades curriculares Introdução à Administração (primeiro ano do curso) e Jogos Empresariais (último ano do curso).

Foi utilizado um roteiro semi estruturado trabalhado de forma coletiva pelos pesquisadores/professores. Ao final do processo didático, os alunos participavam de uma roda de conversa onde relatavam sobre a experiência de gestão vivida de forma simulada e sobre a experiência do uso desse método de aprendizagem.

\section{Resultados e Discussões}

Como principal resultado temos como foi fundamental perceber nos depoimentos dos alunos o quanto eles passaram a respeitar mais a gestão e a importância da formação acadêmica para o exercício da prática.

O roteiro semi estruturado interrogava: sobre a simulação como método de ensino, o que o aluno esperava ao participar daquele método e o que a simulação poderia proporcionar e proporcionou com a unidade curricular. Nesse contexto também foram desenvolvidas atividades lúdicas, dinâmicas de grupos e trabalhos em equipe. 
Inovando a aprendizagem através da utilização do método simulação em unidades curriculares teóricas no curso de administração

Na unidade curricular Jogos Empresariais se desenvolveu vários tópicos da Gestão: negociação, tomada de decisão, produção, estratégias de gestão, marketing, logística, recursos humanos, finanças e visão analítica. Foram vários encontros durante o semestre em curso, onde se desenvolveram ações juntas ou não das temáticas mencionadas a partir de

$\mathrm{Na}$ unidade curricular Introdução à Administração se desenvolveu uma reprodução específica de uma teoria, a Administração Científica. Foi recriado um cenário de linha de produção e foi possibilitado aos alunos vivenciarem o contexto da época e buscarem entender como a teoria aconteceu e ressignificarem-na com outras possibilidades.

O resultado da prática da simulação foi extremamente positivo por várias perspectivas: os alunos afirmaram que ajudou a desenvolver suas habilidades empresariais, ao tempo que aplicavam os conhecimentos teóricos na prática simulada, exercitaram o uso da informação na tomada de decisão, enfrentaram desafios, interagiram e discutiram com os colegas, sentiram as dificuldades de lidar com as minorias e demissões dentro da organização simulada; quanto da participação, os alunos vivenciaram as atividade de forma séria, responsável, ativa, comprometida e válida; a da práxis, aliaram conhecimento de gestão, bem estar coletivo, dentre outros conceitos, e principalmente, que é a tônica desse relato, a do uso do método ativo de aprendizagem chamado simulação, o aluno interagiu com o assunto em estudo, foi estimulado a construir o conhecimento ao invés de somente recebêlo de forma passiva, a atuação dos professores foi de orientação e de interação com as situações e com o contexto, além de proporcionar as descobertas feitas pelos próprios alunos na prática do conhecimento percebido.

\section{Referências}

Abreu, M. C. T. A., \& Masetto, M. T. (1982). O Professor universitário em aula: prática e princípios teóricos. São Paulo: Cortez.

Barbosa, E. F., \& Moura, D. G. (2013). Metodologias ativas de aprendizagem na Educação Profissional e Tecnológica. Boletim Técnico do Senac, Rio de Janeiro, 39(2), 48-67.

Marion, J.C. \& Marion, A.L.C.(2006) Metodologias de ensino na área de negócios: para cursos de administração, gestão, contabilidade e MBA. São Paulo: Atlas.

Moreira, D. A. (2003). A Linguagem da educação: aplicação de algumas ideias de Israel Scheffler. In D. A. Moreira (Org.), Didática do ensino superior: técnicas e tendências. São Paulo: Pioneira Thomson Learning.

Nóvoa, A. (2015). Escola sem escolas? In F.C. Pinto (Coord.), Educação, História e Políticas. Tributo a Rogério Fernandes (pp. 221-239). Lisboa: Edições Piaget.

Paviani, J. (2003). Ensinar, deixar aprender. Coleção Filosofia, 154. Porto Alegre: EDIPUCRS. 